\title{
Movement of light hydrocarbons through limestone: analysis of contaminant composition
}

\author{
Shirin Sepehri, Ender Okandan
}

\begin{abstract}
Spillage of petroleum products in soil, rivers and lakes is a problem since the advent of the petroleum era. Contamination of groundwater is one of the most important hazard of spill because it is a threat to animals, plants as well as human life. Fingerprinting of oil spills plays an important role in order to select the best treatment and cleanup method. Factors such as penetration depth of the oil into the soil, type of oil and polluted soil and the age and degree of contamination determine the efficiency of soil remediation.
\end{abstract}

In this study, an experimental model was used to investigate the movement of a hydrocarbon liquid such as diesel oil and gasoline in soil where crushed limestone was the soil medium. A plexiglass cylinder with three ports at three different depths (in order to collect samples) was constructed. It was filled with crushed limestone. The design enabled to collect samples, analyze them and understand the mechanism of contaminant downward movement. Samples were collected at different time intervals from ports and analyzed by gas chromatography to obtain chemical compositions of the contaminants. Penetration depth of different contaminants at different time intervals were investigated in this study. By comparing behavior of diesel oil and gasoline, it was observed that the downward movement rate of gasoline is higher due to possessing lower viscosity than diesel. So, it reached to the dipper depth at the same time interval. As a result, gasoline spillage requires more rapid action to prevent groundwater contamination. On the other hand, Residual nonAqueous Phase Liquid (NAPL) saturation in this sand pack is higher in the case of viscose contaminant spillage which is diesel oil in this study. The reason is downward movement of the diesel oil is slow and the contaminant has more time to occupy available pore spaces in its downward path. So the concentration of the contaminant would be high. Which leads to critical results to select the best remediation technique.

Keywords: Spillage, gas chromatography, fingerprinting, NAPL, contamination, fingering.

Shirin Sepehri/ Petroleum and Natural Gas Engineering Department Middle East Technical University Ankara/ Turkey

Prof. Dr. Ender Okandan/ Petroleum and Natural Gas Engineering Department Middle East Technical UniversityAnkara/ Turkey

\section{Introduction}

Oil spill from pipelines, gathering stations and failing of storage tanks which occur during exploration, production and transportation of petroleum products can generate series of environmental problems by contaminating soil and groundwater. This will likely lead to effects on public health by means of oral consumption, dermal tangency, breathing or maybe foodstuff chain coverage pathways (Chen, Huang, \& Chakma, 2001). An average of 29 million Litres of petroleum was launched into the waters of North America each year. The majority of spilled oils in environment tend to be fuels (48\%) along with crude oils (29\%)(M.Mudge, 2008). In Korea average amount of spilled petroleum products was about 827 $\mathrm{kl}(1000 \mathrm{~L})$ and the number of seapages were 388 within the last few decade (Yim et al., 2011). It was estimated that in $20 \%$ to $25 \%$ of storage tanks of Canada leakages has occurred. In 1979, nineteen spills occur followed by 35 water well contamination. In 1986, 89145 more wells were contaminated. Between 1979-1987, more than 1000 wells were contaminated by gasoline (Cherry, John, 1987). $11 \%$ to $25 \%$ of oil spills are related to gasoline and diesel spills respectively in Canada each year. As soon as oil has spilled to considerable degree in soil, recovery through digging can be impracticable. In these cases, wells have to be sunk, downstream from the spill, both to extract mobile oil, also to collect water which has percolated via oily soil and thus may always be polluted through soluble ingredients. Recovery of contaminated water is a time consuming process which may continue for many months. Usual surface contamination might be partitioned into various parts:

i. The part of contaminant which is near the surface and dissolved in water. Depending on soil saturation and gravity it can finds its way to the groundwater.

ii. That part of contaminant which remains between soil particles and called residual saturation and,

iii. The part that evaporates into the atmosphere (M. Amro et al., 2013).

The main objective of this study is to investigate the behavior of oil products in porous media. The main problems which was stated here were about contaminant circulation and downward movement which depend on soil type, contamination type and distance from contamination source. An experimental work was conducted in order to simulate migration of different contaminants in the porous medium. Depth of contaminant, movement rate of different contaminants with time at different distances were analyzed.

\section{Materials and Methods}

A model was constructed to meet the goals given above (Fig: 1). The proposed experimental setup is composed of a plexiglass cylinder (Fig: 1(a)) which is characterized by an inner diameter of 4.8 centimeter and length of 49 centimeters. Three ports were located at the distance of 5,15 and 25 centimeters from the bottom of the cylinder for the purpose of sample collection (Fig: 1(b)). These intervals were considered to diagnose penetration depth of contaminant in the column. 
Proc. of the Fourth International Conference on Advances in Civil, Structural and Environmental Engineering - ACSEE 2016. Copyright $(\odot$ Institute of Research Engineers and Doctors. All rights reserved.

ISBN: 978-1-63248-114-6 doi: 10.15224/ 978-1-63248-114-6-21

The column was filled with Midyat unconsolidated limestone $(32 \mathrm{~cm})$ at the lower part (Fig: 1(c)) and the upper part (Fig: 1(d)) was filled with the contaminant. Three valves (Fig: 1(e)) were considered in the system. One is located at the bottom of the column (which is open during the experiment) in order to show when contaminant reaches the bottom of column and collect it in the measurement cylinder. The other two valves were adjusted at the top of column in order to adjust rate of water which was supplied with ISCO pump in order to saturate the sand pack (Fig: 1(f)). During the experiments, samples were collected in different time intervals and were analyzed by gas chromatography to determine the composition of hydrocarbon fractions. A sieve which was smaller than size of the grains was located at the bottom of the sand pack to prevent any sand loss during the experiment (Fig: 1(g)). Moreover, porosity and permeability of porous media were measured. Dimensions of the core holder are listed in the table below:

Table 1: Dimensions of core holder and properties of the limestone packed column.

\begin{tabular}{|l|c|}
\hline $\mathrm{L}_{\mathrm{c}}$ (Length of cylinder, $\left.\mathrm{cm}\right)$ & 49 \\
\hline $\mathrm{ID}_{\mathrm{c}}$ (Inner diameter od cylinder, $\left.\mathrm{cm}\right)$ & 4.8 \\
\hline $\mathrm{A}_{\mathrm{c}}\left(\right.$ Area of Cylinder, $\left.\mathrm{cm}^{2}\right)$ & 18.1 \\
\hline $\mathrm{V}_{\mathrm{c}}\left(\right.$ Cylinder volume, $\left.\mathrm{cm}^{3}\right)$ & 886.7 \\
\hline Grain size $(\mu \mathrm{m})$ & $88-297$ \\
\hline Permeability $(\mathrm{mD})$ & 785.1 \\
\hline Porosity, $\Phi$ & $40.1 \%$ \\
\hline Vs $\left(\right.$ Volume of cylinder filled with sand pack, $\left.\mathrm{cm}^{3}\right)$ & 579.2 \\
\hline Pore volume $\left(\mathrm{cm}^{3}\right)$ & 232.3 \\
\hline Limestone density, $\rho_{\mathrm{s}}\left(\frac{\mathrm{gr}_{\mathrm{cm}}^{3}}{)}\right.$ & 2.32 \\
\hline
\end{tabular}

In order to observe changes in sand pack, samples were collected from the ports and analyzed in laboratory by gas chromatography.

\section{A. Contaminant Characteristics}

In this study, the applied contaminant in the experiments were diesel oil with a density of $0.8340 \mathrm{gr} / \mathrm{cm}^{3}$ at $15^{\circ} \mathrm{C}$ and gasoline with a density of $0.73 \mathrm{gr} / \mathrm{cm}^{3}$. According to the American Petroleum Institute, they can be classified as light hydrocarbons. The chemical compositions of the contaminants were determined by using gas chromatography.

Contaminants properties which were utilized in this study are listed in Table (2).

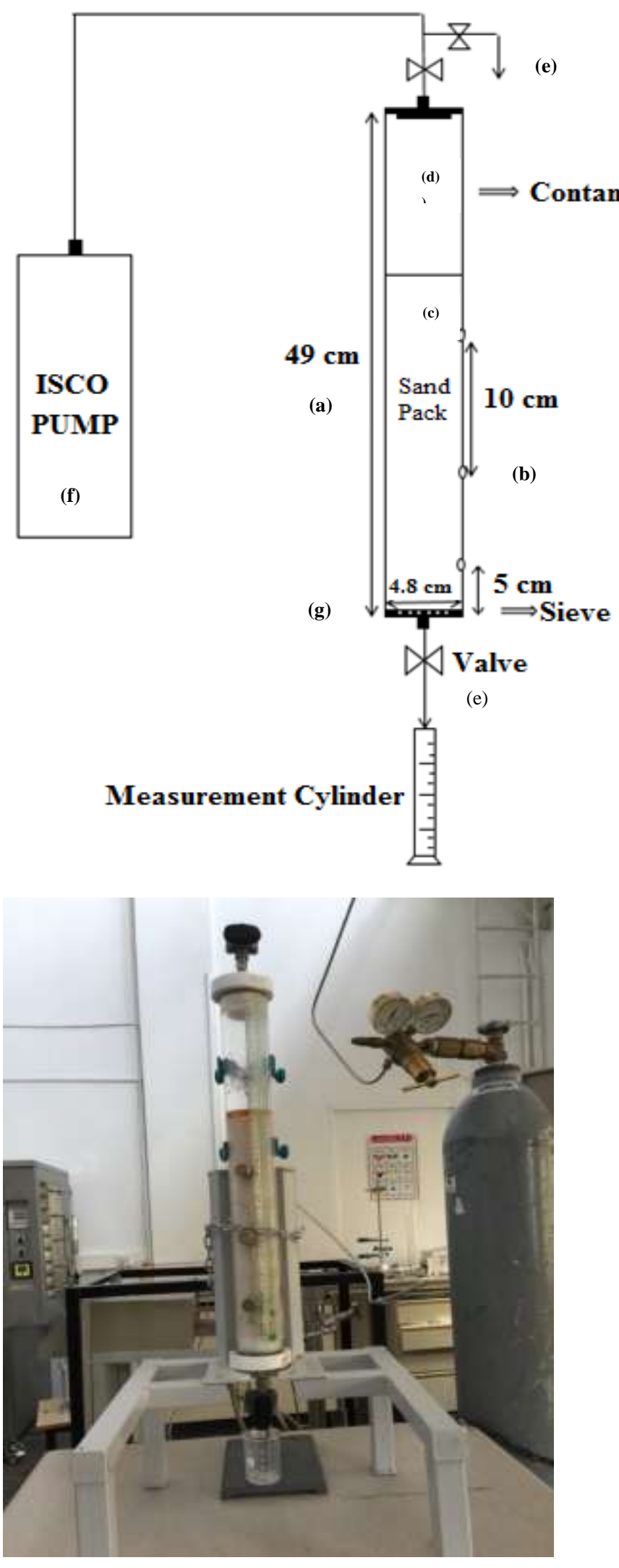

Figure 1: Experimental Setup. 
Proc. of the Fourth International Conference on Advances in Civil, Structural and Environmental Engineering - ACSEE 2016. Copyright $(\odot$ Institute of Research Engineers and Doctors. All rights reserved.

ISBN: 978-1-63248-114-6 doi: 10.15224/ 978-1-63248-114-6-21

Table 2: Properties of fluids used as contaminant.

\begin{tabular}{|l|c|}
\hline Water saturation (\%) & 53.3 \\
\hline Water density, $\rho_{\mathrm{W}}\left(\frac{\mathrm{gr}}{\mathrm{cm}^{3}}\right)$ & 1.00 \\
\hline Density of diesel oil, $\rho_{\mathrm{d}}\left(\frac{\mathrm{gr}}{\mathrm{cm}^{3}}\right)$ at $25^{\circ} \mathrm{C}$ & 0.8430 \\
\hline Density of gasoline $\rho_{\mathrm{g}}\left(\frac{\mathrm{gr}}{\mathrm{cm}^{3}}\right)$ at $25^{\circ} \mathrm{C}$ & 0.72 \\
\hline Contaminant Volume $\left(\mathrm{cm}^{3}\right)$ & 54.3 \\
\hline Gasoline viscosity $(\mathrm{cp})$ at $20^{\circ} \mathrm{C}$ & 0.6 \\
\hline Diesel viscosity $(\mathrm{cp})$ at $25^{\circ} \mathrm{C}$ & 4.746 \\
\hline
\end{tabular}

\section{B. Sample Collection}

Three ports which can be opened and closed were designed to get samples from inside the sand pack. In order to collect samples, test tubes with 0.25 inch $(0.635 \mathrm{~cm})$ in diameter and $8 \mathrm{~cm}$ in length were used. Tubes were pushed into the sand pack from the ports and then pulled back and samples were collected separately in a small glass jars with lids. A total of 33 samples were collected from three ports at 11 time intervals during the experiments.

\section{Experimental Procedure}

The limestone was crushed to $88 \mu \mathrm{m}$ (micro meter) to 297 $\mu \mathrm{m}$ size. It has been assumed that during experiment no chemical reaction was occurring between the materials in the circulating fluid. Unconsolidated limestone was packed in a cylinder and was fully saturated with water and then displaced with air. Since the crushed limestone in the system was water wet, when air was injected into the system, water from larger pores was displaced. The remaining water saturation in smaller pores is defined as irreducible water saturation which was $53.3 \%$. Then, $54.3 \mathrm{~cm}^{3}$ contaminant was put at the top of sand pack.

In the first experiment diesel oil was used as contaminant. 33 samples were collected during the experiment. 18 samples were collected at $30^{\text {th }}, 60^{\text {th }}, 90^{\text {th }}, 120^{\text {th }}, 180^{\text {th }}, 240^{\text {th }}$ and three were collected at $1440^{\text {th }}$ minute from three ports. Then the rate of contaminant downward movement was calculated for each time interval in each experiment. Diesel oil downward movement rate in the first experiment is mentioned in table 3.

Table 3: Rate of diesel downward movement in sand pack

\begin{tabular}{|c|c|c|}
\hline Time (min) & $\begin{array}{c}\text { Amount of diesel infiltrated } \\
\text { in sand pack }\left(\mathbf{c m}^{\mathbf{3}}\right)\end{array}$ & $\begin{array}{c}\text { Rate } \\
\left(\mathbf{c m}^{\mathbf{3}} \mathbf{/ m i n}\right)\end{array}$ \\
\hline 30 & 18.1 & 0.6 \\
\hline 60 & 24.7 & 0.41 \\
\hline 120 & 27.1 & 0.23 \\
\hline 180 & 31.7 & 0.17 \\
\hline 240 & 36.2 & 0.15 \\
\hline 400 & 54.3 & 0.135 \\
\hline
\end{tabular}

The other experiment was done in order to observe downward movement behavior of gasoline in sand pack. Gasoline downward movement rate in the second experiment is mentioned in table 4 .

Table 4: Rate of gasoline downward movement in sand pack

\begin{tabular}{|c|c|c|}
\hline Time (min) & $\begin{array}{c}\text { Amount of gasoline } \\
\text { infiltrated in sand pack }\left(\mathbf{c m}^{\mathbf{3}}\right)\end{array}$ & Rate $\left(\mathbf{c m}^{\mathbf{3}} / \mathbf{m i n}\right)$ \\
\hline 5 & 18.1 & 3.6 \\
\hline 10 & 30.8 & 3.08 \\
\hline 15 & 36.2 & 2.41 \\
\hline 20 & 38 & 1.9 \\
\hline 30 & 45.25 & 1.5 \\
\hline 40 & 54.3 & 1.35 \\
\hline
\end{tabular}

Subjected to benzene (one of the components of gasoline) for long time can cause diseases like cancer and aplastic anemia. Nausea, sleeping disorders, unconsciousness and even death are effects of inhaling toluene in high levels for a short time. So, it is very important to follow behavior of pollutant components after seapage of contaminant.

Sand pack was fully saturated with water and displaced with air. Then, $54.3 \mathrm{~cm}^{3}$ of gasoline was put at the top of sand pack. In total 33 samples were collected in two days. 18 samples were collected at $30^{\text {th }}, 60^{\text {th }}, 90^{\text {th }}, 120^{\text {th }}, 180^{\text {th }}$ and $240^{\text {th }}$ minutes. Samples were analyzed in detailed hydrocarbon analysis gas chromatography. As the GC gives mass percent of each component in gasoline, in this experiment samples were not put in the oven.

\section{Analysis of Samples}

After carefully collecting samples, constant volume of hexane $(3 \mathrm{~mL})$ was used as solvent to extract contaminant from the samples. Then the mixture of hexane and contaminant was analyzed in gas chromatography. The composition of hydrocarbon fractions was analyzed using a program called "Simdis" on the gas chromatogram. Components of a mixture is separated based on boiling point (or vapor pressure) differences. Subsequently, the remaining part of samples which is the mixture of soil, water and remaining hexane and contaminant were put in oven in order to separate and calculate the amount of contaminant, water and crushed sand of each sample in the first four experiments. Gas chromatography is used in order to separate and analyze components which can be vaporized without decomposition. Components of a mixture separate based on boiling point (or vapor pressure) differences in gas chromatography. In this study, sample analysis was done with an Agilent 7890A with three detectors with four detector signals. Maximum temperature ramp rate is $120^{\circ} \mathrm{C} / \mathrm{min}$ for column oven. The range of temperature is between $+4^{\circ} \mathrm{C}$ to $450^{\circ} \mathrm{C}$ and the carrier gas is helium. Gas chromatograph gives some information about the hydrocarbon components. From the gas chromatography, it can be observed that diesel oil consists of many hydrocarbons which were in the range of $\mathrm{C}_{10}$ to $\mathrm{C}_{32}$ with 
different proportions as (mg) in liter of solution.In order to have a good comparison between the samples, amount of each component as milligram was calculated. On the other hand, beside the samples, compositional fraction of diesel itself in gas chromatograph in three different volumes, namely $0.1,0.5$ and 1 milliliters were analyzed. As the concentration of components are close in three different volumes, the average of concentrations was calculated and utilized as reference concentration for each component.

\section{Results and Discussions}

As the gas chromatogram gives information about the amount of each component of contaminant, the concentration of each component was obtained by dividing mass of each component in milligram to the total amount of contaminant in sample. Results show that the alkane components of diesel oil could be divided into three classes. The first class involves components containing hydrocarbons between $\mathrm{C}_{10}$ to $\mathrm{C}_{16}$. This class of hydrocarbon components has moderate level of concentration in diesel oil. The second class, having the highest concentration in diesel oil, is related to the components containing hydrocarbons $\mathrm{C}_{17}$ and $\mathrm{C}_{18}$. Finally, the third class involves components containing hydrocarbons between $\mathrm{C}_{19}$ to $\mathrm{C}_{32}$, which has the lowest amount in diesel oil.

From all the hydrocarbons existing in all three classes, to have a more efficient discussion, 8 hydrocarbons were taken into consideration. These hydrocarbons are $\mathrm{C}_{10}, \mathrm{C}_{11}, \mathrm{C}_{12}, \mathrm{C}_{17}$, $\mathrm{C}_{18}, \mathrm{C}_{26}, \mathrm{C}_{27}$ and $\mathrm{C}_{28}$. Concentration of each hydrocarbon was calculated in each sample by dividing the amount of hydrocarbon (which was obtained from gas chromatograph) by total amount of contaminant in sample (which was calculated after separation stages by vaporization process in oven). Besides, $0.1,0.5$, and $1 \mathrm{~mL}$ of diesel oil were analyzed separately in gas chromatograph and the average concentration of all eight components were calculated to have more reliable comparing results.

\section{A. Contaminant Depth}

The goal of first experiment was to investigate the behavior of diesel oil. Figure (2) shows that the concentration of selected components of samples which were collected at $60^{\text {th }}, 120^{\text {th }}$ and $240^{\text {th }}$ minutes from three different ports. The ports were located at 7,17 and $27 \mathrm{~cm}$ from the top of sand pack. Concentration of components at $60^{\text {th }}$ minutes is shown by grey series while green and blue series show concentration of $120^{\text {th }}$ and $240^{\text {th }}$ minutes of experiment. Moreover, the red series shows concentration of components in diesel oil which were analyzed in gas chromatography separately.

Considering Figure (2), there is an obvious increment in concentration of all components with time in all three ports. In all series, $\mathrm{C}_{26}, \mathrm{C}_{27}$ and $\mathrm{C}_{28}$ have the lowest and $\mathrm{C}_{17}$ and $\mathrm{C}_{18}$ have highest concentrations. In the first port which is the nearest port to the top of sand pack, concentration of all components are high in comparison to the second and third ports which are located in the middle and bottom of the column, respectively. At all the time steps, concentration of all the hydrocarbons is significant in the first port, unlike the second and the third ones. In the second port, concentration of all components were increased with time, but the level of this increment is less compared to the first port. Components concentration are negligible in the third port at the same time steps with regards to the first and second ports. In order to see the concentration changes, secondary $\mathrm{Y}$-axis with lower scale were considered in the second and third ports. The related $\mathrm{x}$ and $y$ axis is shown for each series with the series color.

Furthermore, amount of each component in each sample to the original amount of each component in pure diesel oil was calculated for each time step. It can be concluded that in the first port, concentration of all components between the first and second hour of the experiment increased $95 \%$ in average. In the second and third ports, it is $47 \%$ and $41 \%$ respectively. With time, this increment decreases in the first port and increases in the second and third ports.
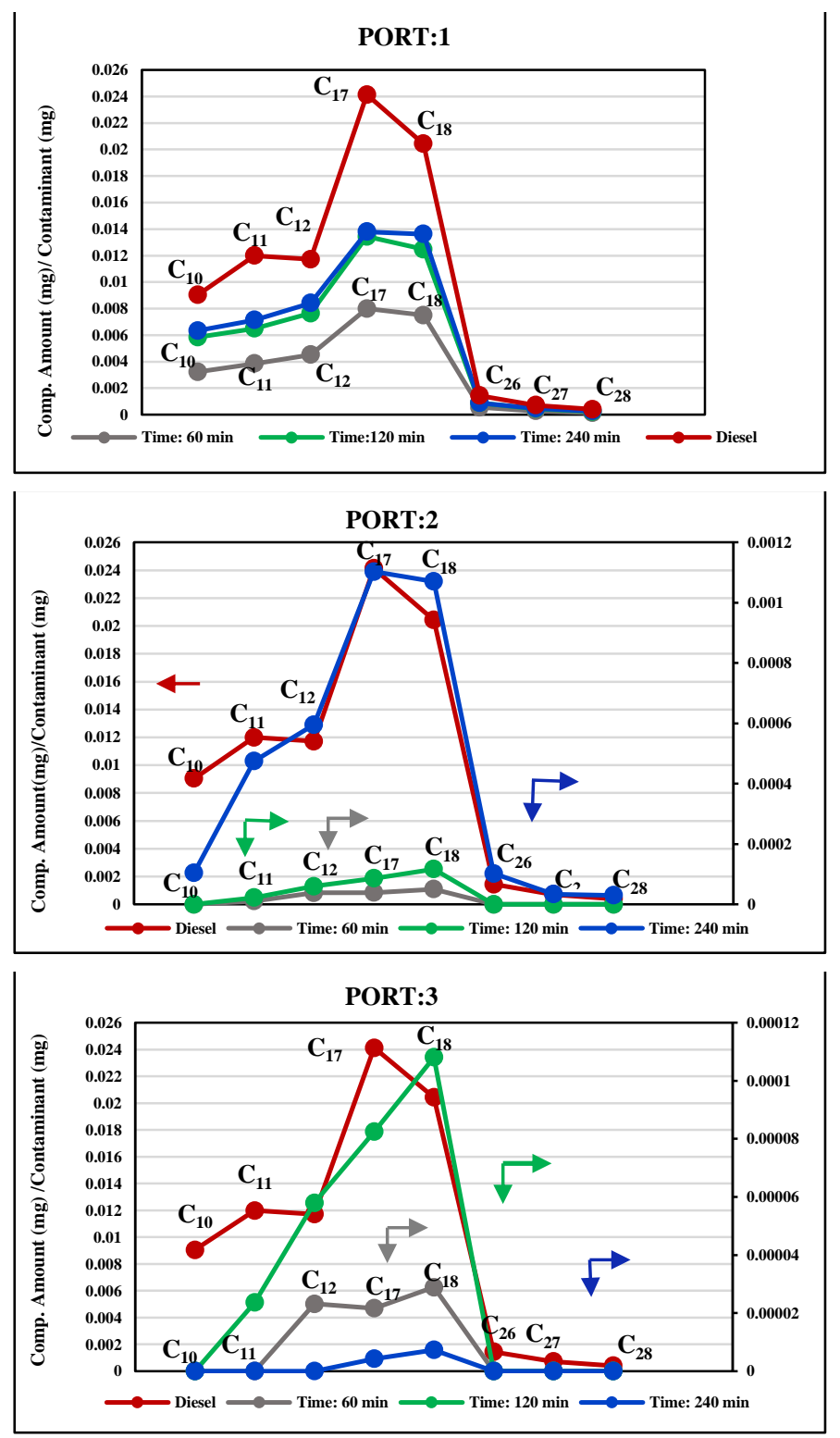

Figure 2: Diesel concentration in three ports at different time intervals. 
Proc. of the Fourth International Conference on Advances in Civil, Structural and Environmental Engineering - ACSEE 2016. Copyright $(\odot$ Institute of Research Engineers and Doctors. All rights reserved.

ISBN: 978-1-63248-114-6 doi: 10.15224/ 978-1-63248-114-6-21

Figure (3) shows concentration of components in three ports after 24 hours (1440 minutes). In comparison to the results of the first day, concentration of all the components was increased with time in all the ports. Concentration increment in the second port is more perceptible compared to the first port because of mass movement of the contaminant with time.

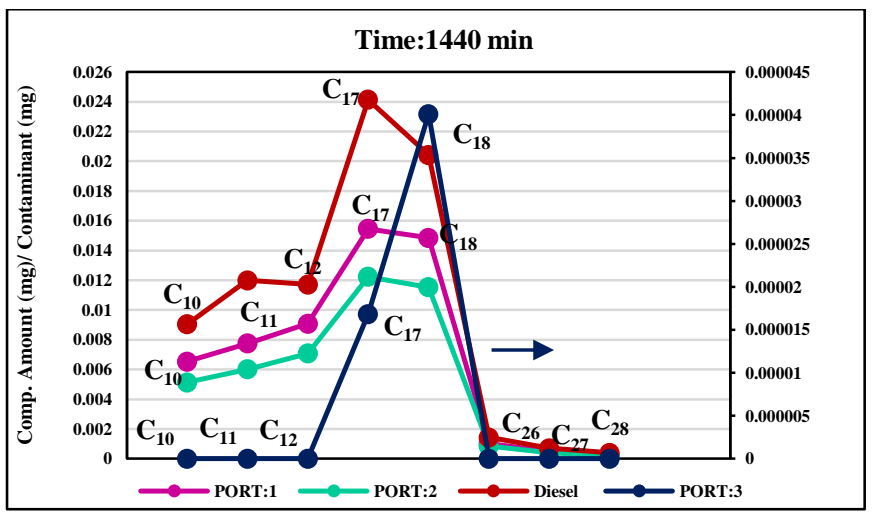

Figure 3: Diesel concentration in three ports at 1440th minute.

\section{B. Gasoline as the Contaminant}

The second experiment was done with gasoline as the contaminant. The same amount of gasoline as the contaminant $54.3 \mathrm{~cm}^{3}$ ) was placed at the top of sand pack. All the gasoline moved into the sand pack in 40 minutes, while this time for diesel oil was 400 minutes for diesel oil. Figure (4) (shows the percolation rate of gasoline and diesel oil versus time. Downward movement rate of gasoline was 10 times more than diesel oil. Concentration of gasoline components also increased with time in all three ports.

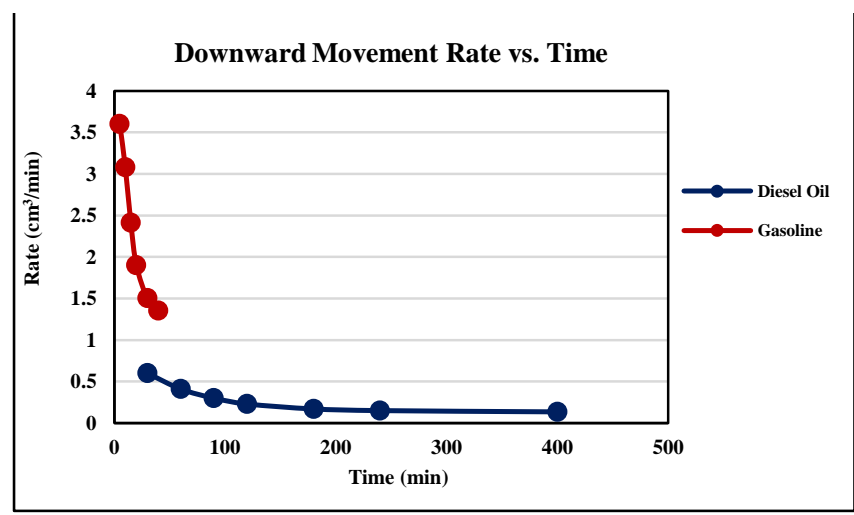

Figure 4: Downward movement rate of diesel oil and gasoline vs. time.

\section{Conclusion}

In this survey, behavior of liquid hydrocarbons percolation through sand was investigated with an experimental model. Diesel oil and gasoline were used as contaminant in two different experiments. After discussing the result, it was investigated that:
The more the depth, The less the concentration of components. Concentration of the components in the first port (which is the nearest port to the top of the sand pack) was high in comparison to the second and the third ports (which are located at the middle and bottom of the plexiglass cylinder, respectively). The lighter the contaminant, the faster the downward movement rate. The downward movement rate of gasoline (less viscous) is faster than diesel oil (10 times faster). Which means that it could reach to the dipper depth at the same time interval than diesel oil. Consequently, more rapid action is needed in the case of gasoline spillage in order to prevent groundwater contamination.

On the other hand, residual NAPL saturation is higher in the case of viscous contaminant. This is because of the slower downward movement of the pollutant from the pores to the pathways and therefore the occupation of spaces is dominant to downward movement. So the concentration of the contaminant would be high. Time, on the other hand plays an important role in contamination process. As the time passes, the concentration of the pollutant in all the ports increases. So, it is very important to decide on the best remediation technique as soon as possible in order to reduce hazardous consequences of the spillage.

\section{References}

[1]. Chen, Z., Huang, G. H., \& Chakma, A. (2001). Simulation and Assessment of Subsurface Contamination Caused by Spill and Leakage of Petroleum Products - A Multiphase, Multicomponent Modelling Approach. In Petroleum Conference of The South Saskatchewan Section (Vol. 40). Regina: Petroleum Society of Canada.

[2]. M.Mudge, S. (Ed.). (2008). Methods in Environmental Forensics. New York: CRC Press.

[3]. Yim, U. H., Ha, S. Y., An, J. G., Won, J. H., Han, G. M., Hong, S. H., ... Shim, W. J. (2011). Fingerprint and weathering characteristics of stranded oils after the Hebei Spirit oil spill. Journal of Hazardous Materials, 197, 60-9. http://doi.org/10.1016/j.jhazmat.2011.09.055.

[4]. Cherry, John(University of Waterloo, C. (1987). Groundwater Contamination By Petroleum Products. In 12th World Petroleum Congress. Houston, Texas.

[5]. Amro, M. M., Benzagouta, M. S., \& Karnanda, W. (2013). Investigation on crude oil penetration depth into soils. Arabian Journal of Geosciences, 6(3), 873-880. http://doi.org/10.1007/s12517-011-0392-6.

\section{Shirin Sepehri}

MS.c in Petroleum and Natural Gas Engineering.

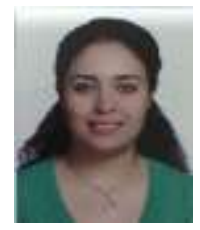

